EPiC Series in Engineering
Volume 3, 2018, Pages 2318-2326
HIC 2018. 13th International
Conference on Hydroinformatics

\title{
Study on Design Specification of Water Allocation Projects' Information System
}

\author{
Xuehong Wen \\ General Institute of Water Resources and Hydropower Planning and Design, MWR, P. R. China \\ 58569515 @qq. com
}

\begin{abstract}
In China, recently, quite a few water allocation projects have built its information systems. However, the design criteria of information systems are usually chaotic, and sometimes it is various degrees of over-developed. This paper consider that a design specification of information systems for water allocation projects must be issued soon. Depend on the current situation of information system design, some suggestion was proposed in this paper to discuss how to draft a design specification for water allocation project information system. The design specification will regulate the developing of information systems, save water resources, and finally improve the management level of water allocation projects.
\end{abstract}

\section{Instruction}

At present, the engineers commonly begin to design information systems in feasibility research stage of project. But, from the perspective of whole country, the design criteria of information systems are chaotic, and the design scale of information system and water project are usually not matched. The causes of this problems are the differences in the level of regional economic development and the designers' understanding. However, the most fundamental reason is that at present China does not yet have a special design code to guide and to constrain the design of information systems for such a projects. Therefore, it is urgent to issue an appropriate specification to standardize the design of information system and enhance the operation and management level of water allocation project.

Based on the operation and management demands of water allocation project and the status quo of information system design, some preliminary suggestions for compiling information system design specification are proposed in this paper. 


\section{Water resources allocation projects}

Depend on the engineering tasks, water allocation projects include urban and rural water supply projects, agricultural irrigating projects, ecological improvement projects and comprehensive application of the above three. The typical engineering measure of water allocation projects is building a dam to store up water, and then the water will be delivered to users through the longdistance transmission and distribution facilities such as canal, aqueduct, pipe, tunnel, inverted siphon, storage reservoir, sluice, valve, etc. Sometimes, a pump station or hydropower station may located on the water supplying route. ${ }^{[1]}$

The water allocation project covers a wide range, so the managers generally set up submanagement units along the water supplying route. Above the sub-management layer, there usually are dispatch and spare dispatch centre, and below the sub-management layer there are controlled buildings. Therefore, a typical management structure is divided into at least three levels. ${ }^{[2]}$ As shown in Figure 1 below.

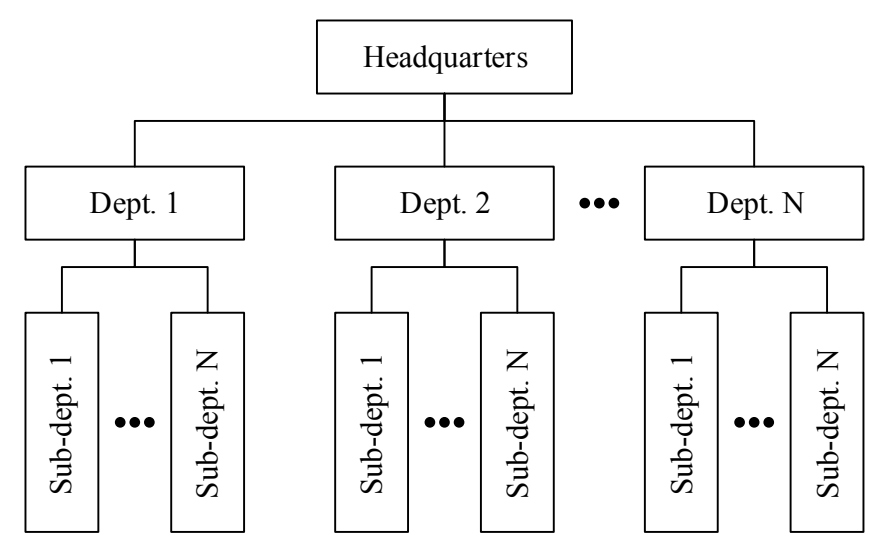

Figure 1: A typical management structure

\section{Information system of water allocation projects}

Water allocation project information system can be regarded as the integration of industrial control network and enterprise information network. The industrial control network of water allocation projects has become a very large system due to its large geographical span and lots of network nodes. The typical network structure of water allocation project information system is shown in Figure 2. 


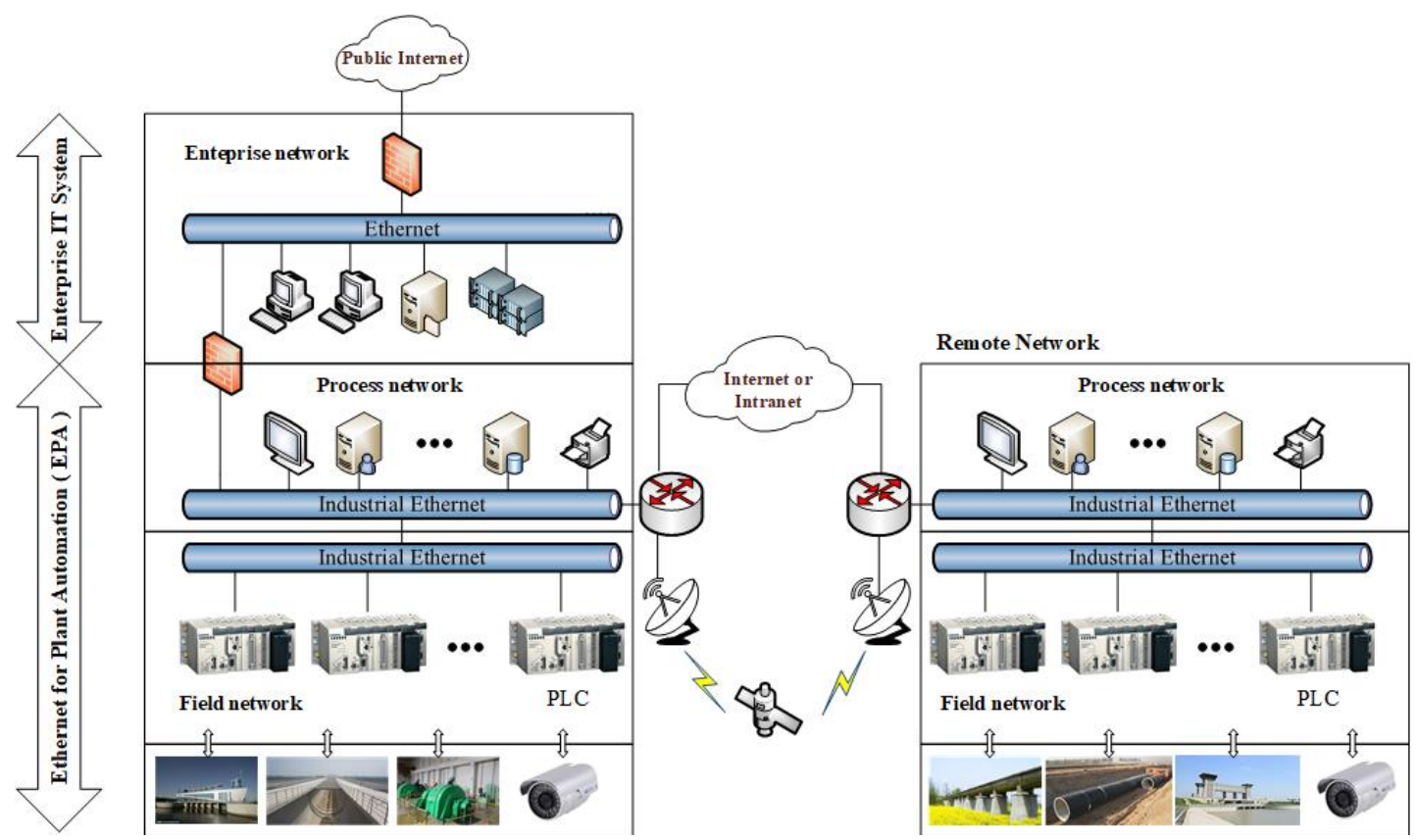

Figure 2: Typical network structure of water allocation project information system

Through years of exploration and practice, China's water conservancy informatization infrastructure has begun to take shape, business support has gradually increased and auxiliary facilities have improved significantly. By now, large-scale of data acquisition, high-speed data transmission and efficient remote control of water conservancy project have laid a solid foundation for the water resource dispatching decision support system. The development of water conservancy informatization infrastructure not only enhances the modernization of water allocation project operation and dispatching but also more strongly supports the planning, design and management of water allocation projects.

Table 1 Typical function demands of water allocation project information system

\begin{tabular}{|c|c|c|c|c|c|}
\hline \multicolumn{2}{|l|}{ Projects } & DZ & YJ & CL & YH \\
\hline \multicolumn{2}{|c|}{ Engineering tasks } & \multicolumn{4}{|c|}{$\begin{array}{l}\text { Urban and rural water supply, agricultural } \\
\text { irrigating, ecological improvement, etc. }\end{array}$} \\
\hline \multirow{4}{*}{$\begin{array}{l}\text { Characteris } \\
\text { tics of } \\
\text { projects }\end{array}$} & Project scale & I & $\mathrm{I}$ & $\mathrm{I}$ & I \\
\hline & Distance of main canal $(\mathrm{km})$ & 664 & 1049 & 1277 & 98 \\
\hline & Water diversion flow $\left(\mathrm{m}^{3} / \mathrm{s}\right)$ & 135 & 300 & 350 & 70 \\
\hline & Annual water diversion $\left(10^{9} \mathrm{~m}^{3}\right)$ & 3.4 & 4.3 & 13 & $\begin{array}{l}1.39 \\
5\end{array}$ \\
\hline \multirow{3}{*}{$\begin{array}{l}\text { Remote } \\
\text { controlled } \\
\text { objects }\end{array}$} & Sluice or valve & 122 & 9 & 318 & 52 \\
\hline & Pump station & 1 & 10 & 1 & 2 \\
\hline & Hydropower plant & 2 & 0 & 0 & 1 \\
\hline \multirow{3}{*}{$\begin{array}{l}\text { Function } \\
\text { demands }\end{array}$} & Hydraulic data acquisition & $\checkmark$ & $\checkmark$ & $\checkmark$ & $\checkmark$ \\
\hline & Video monitoring & $\checkmark$ & $\checkmark$ & $\checkmark$ & $\checkmark$ \\
\hline & Building safety monitoring & $\checkmark$ & $\checkmark$ & $\checkmark$ & $\checkmark$ \\
\hline
\end{tabular}




\begin{tabular}{|c|c|c|c|c|c|}
\hline & Water quality monitoring & Online & Online & Online & $\begin{array}{l}\text { Onli } \\
\text { ne }\end{array}$ \\
\hline & Meteorological monitoring & $\checkmark$ & $x$ & $x$ & $\checkmark$ \\
\hline & Soil moisture monitoring & $x$ & $x$ & $x$ & $x$ \\
\hline & Optimal dispatching & $\checkmark$ & $x$ & $\checkmark$ & $\checkmark$ \\
\hline & Video conference & $\checkmark$ & $\checkmark$ & $\checkmark$ & $\checkmark$ \\
\hline & GIS & $\checkmark$ & $\checkmark$ & $\checkmark$ & $\checkmark$ \\
\hline & BIM & $\checkmark$ & $\checkmark$ & $x$ & $x$ \\
\hline & Large screen & $\checkmark$ & $\checkmark$ & $\checkmark$ & $\checkmark$ \\
\hline & Remote backup & $\checkmark$ & $\checkmark$ & $\checkmark$ & $\checkmark$ \\
\hline Layers of con & trol & 2 & 2 & 3 & 3 \\
\hline \multicolumn{2}{|c|}{ Communication } & \multicolumn{4}{|c|}{ Laying optical cable + Renting circuit } \\
\hline Budgetary es & imate of project $\left(10^{6} \mathrm{CNY}\right)$ & 473 & 213 & 2261 & 282 \\
\hline
\end{tabular}

Table 1 reflects China's 4 large-scale water diversion projects. The data come from the projects' preliminary design report. It can be seen that the number of controlled objects for each water allocation project is very large, and some new technologies have been introduced into the system design. However, the author found a problem in many established water projects is that the SCADA system and the main project can put into service at the same time, but the development of decision support system (DSS) in upper layer of system is very slow. It is because that in order to put the project into service earlier, all parties concerned to the project only pay attention to the realization of SCADA. There is no synchronous research on dispatch model and optimal algorithm during the integrating of information system. Furthermore, some of the water allocation projects actually are easy to operate. The operators can well work without DSS. So, they no longer focus on the information system construction.

In order to avoid the above and other problems in information system development, the author considers that it is necessary to compile a proper design specification to guide and constrain the design of information system. In this paper, based on several key aspects of system design, how a design specification compiled will be discussed, and some advices to current design situation are proposed.

\section{Design specification of information system}

\subsection{Purpose of design specification compiling}

The purpose of compiling a design specification is to standardize the design of water allocation projects information system to ensure that the system is moderate in scale. Furthermore, information system must be run steadily, reliably and safely to improve the operation and management level of projects and to improve the utilization rate of water resources.

\subsection{Scope of application}

Recently, the main task of water resources allocation project is water supply, agricultural irrigation and ecological improvement. Therefore, the scale of the project is mainly based on the diversion stream flow, annual water diversion volume, irrigated area and importance of water supply objects. 
Table 2 Index of project scale ${ }^{[3]}$

\begin{tabular}{ccccc}
\hline & & \multicolumn{3}{c}{ Factors of consideration } \\
\cline { 3 - 5 } Index & Scale & $\begin{array}{c}\text { Stream flow } \\
\left(\mathrm{m}^{3} / \mathrm{s}\right)\end{array}$ & $\begin{array}{c}\text { Annual water diversion } \\
\left(10^{8} \mathrm{~m}^{3}\right)\end{array}$ & $\begin{array}{c}\text { Irrigated area } \\
\left(10^{3} \mathrm{ha}\right)\end{array}$ \\
\hline I & Large-scale 1 & $\geq 50$ & $\geq 10$ & $\geq 100$ \\
II & Large-scale 2 & $50 \sim 10$ & $10 \sim 3$ & $100 \sim 33.3$ \\
III & Middle-scale & $10 \sim 2$ & $2 \sim 1$ & $33.3 \sim 3.3$ \\
IV & Small-scale & $<2$ & $<1$ & $<3.3$ \\
\hline
\end{tabular}

In order to ensure that the information system is built up in a timely and effective way, according to the construction experience of the existing projects, it is recommended that the largescale water allocation project has higher priority to develop an information system. According to the actual demands, the medium-scale projects may implement the suggestions by reference. It should be noted that the scale of a project is not the only aspect of judging whether or not to develop information system. In fact, to operate a multi-task project is actually very complicated. Because, it always has too many controlled objects, even it is a medium-scale project. In this situation, the engineers still need the information system's help to provide an overall optimal control decision. Therefore, a more reasonable approach needs to consider the complexity of engineering tasks and the number of controlled objects.

\subsection{Demand analysis}

Demand analysis is the foundation of information system design. Both functional requirements and performance requirements should reflect a moderately advanced design concept, which could ensure the sustainable and stable operation of the system.

This paper suggests that the specification should clearly indicate the most basic function requirements for each kind of project, and give us some optional functions to appropriate promote the design criterion. Combining with the current situation of information system design, the suggested function demands for each kind of project are listed in following table. The data in table 3 should be obtained firstly from the existing system. Medium-scale projects may implement the suggestions by reference.

Table 3 Functional demands of information system for large-scale project

\begin{tabular}{|c|c|c|}
\hline Tasks & Basic functional demands & Optional function demands \\
\hline $\begin{array}{l}\text { Urban and } \\
\text { rural water } \\
\text { supply }\end{array}$ & $\begin{array}{l}\text { - Flow monitoring } \\
\text { - Water level monitoring } \\
\text { - Velocity of flow } \\
\text { - Pressure } \\
\text { - Water quality } \\
\text { - Video } \\
\text { - Building safety monitoring } \\
\text { - Sluice/valve local control } \\
\text { - Pump station local control }\end{array}$ & $\begin{array}{l}\text { - Online water quality monitoring } \\
\text { - Sluice/valve remote control } \\
\text { - Pump station remote control } \\
\text { - Hydropower plant remote control } \\
\text { - Video conference } \\
\text { - Remote backup } \\
\text { - Large screen display system } \\
\text { - 2D/3D GIS } \\
\text { - BIM }\end{array}$ \\
\hline $\begin{array}{l}\text { Agricultural } \\
\text { irrigating }\end{array}$ & $\begin{array}{l}\text { - Hydropower plant local control } \\
\text { - Dispatching telephone system } \\
\text { - Optimal dispatching } \\
\text { - Network security system } \\
\text { - Operation and maintenance system } \\
\text { - OA }\end{array}$ & $\begin{array}{l}\text { - Meteorological monitoring } \\
\text { - Soil moisture monitoring } \\
\text { - Sluice/valve remote control } \\
\text { - Pump station remote control } \\
\text { - Hydropower plant remote control } \\
\text { - Video conference }\end{array}$ \\
\hline
\end{tabular}


- 2D/3D GIS

- BIM

\begin{tabular}{ll}
\hline & $\bullet$ Online water quality monitoring \\
\cline { 2 - 3 } & - Sluice/valve remote control \\
Ecological & $\bullet$ Pump station remote control \\
improvement & $\bullet$ Hydropower plant remote control \\
& $\bullet$ Video conference \\
& $\bullet 2 \mathrm{D} / 3 \mathrm{D}$ GIS \\
& $\bullet \mathrm{BIM}$ \\
\hline
\end{tabular}

For system performance demands, it is difficult to uniformly and comprehensively stipulate in the design specification. Even so, a principle requirement should be, at least, proposed in the specification to ensure that the system structure or hardware performance can meet various operating requirements about response speed, scalability and availability. The information system must operate steadily and reliably and safely.

\subsection{System design requirements}

System design is a very important step to the realization of system requirements. In this section, the author analysed the current problems in system design works, and summarized the differences of information system design on following several aspects. And then, the suggestions were proposed to make information system design standardized.

\section{Technical scheme comparison}

The detailed design of the information system should provide users with a stable, safe and reliable solution. However, any good design should meet the economical requirements. Therefore, the specification should explicitly require that all solutions of key subsystems in the information system must be determined through technical and economical comparison. In this paper, the important subsystem referred to a part that usually has a great influence on system reliability and total cost, including but not limited to communication system, networking mode, storage system, disaster recovery system, equipment selection, water resource control strategy, etc.

Before the determining of water resources dispatching and control solution, the dispatching model should have studied and the preliminary results should be obtained. This will be more helpful to the implementing of optimal dispatching system.

\section{Water quality monitoring}

Continuously water quality monitoring is very necessary for a project with task of urban and rural water supply. ${ }^{[4]}$ But due to the daily maintenance workload and high cost, the automatic water quality monitor station is a big burden to operation unit. Therefore, this paper suggests that automatic monitoring station could be located at important water sources and several key controlling section. The artificial water quality monitoring on other sections is used as a complement. For the water allocation projects with other tasks, such as agricultural irrigation projects and ecological improvement projects, the regularly artificial monitoring is enough for project management requirement. Because of this kind of projects is not sensitive to the water quality, and the running time of them is also very short.

\section{Large screen display system.}

The function and advantage of large screen display system is needless to mention here, but because of its wide variety and rapid technological updating, the design of large screen display system 
is quite different. In the current situation of water conservancy project monitoring system, many control centres do not turn on large screen in daily monitoring to save cost, they usually monitor the project only through screens of workstation. So, this mode of usage of large screen is extremely unreasonable. Therefore, it is suggests that if a large screen display system is needed, this system should be used simultaneously for engineering monitoring and video conferencing to improve its utilization ratio.

\section{Communication system}

Network structure and transmission mode have great influence on the total cost of information system. Currently, video monitoring is widely adopted, so the optical fibre is basically the preferred option, which has large-capacity and reliable transmission. ${ }^{[5][6]}$ If the construction unit chooses to build the optical cable their own, the hundreds kilometres cable will cost very much in initial construction cost and later maintenance expenditure. Today, public wired and wireless transmission network, satellite communications network are more convenient to use. So, access methods of engineering nodes which located along the water supplying route need to be determined through detailed technical and economical comparison. The final solution should be reliable, economical and maintainable.

In addition, in the current situation of information system design, the calculating method of communication bandwidth is different in many design companies. Obviously, the larger the communication bandwidth is, the higher the cost of system is, and the unnecessary waste is likely to happen. Therefore, the calculation methods of primary technical parameters and how to determine the future extension space are all should be explicitly defined in this specification. The technical parameters mainly refers to capacity of storage, bandwidth of voice and video transmission, size of the large screen, etc.

\section{Disaster recovery system}

The design of disaster recovery system and the requirements of disaster recovery are also have differences of design in many company. From a practical and economical perspective, this paper considers that urban and rural water supply projects which have the features of strong continuity should configure disaster recovery system. The agricultural irrigation projects and ecological improve projects operate seasonally, so there isn't necessary to configure disaster recovery system.

In addition, compared with other industries, the real-time and continuous requirements of water resource allocation project information system are not high. Once the information system is interrupted, the project can maintain the current stable state for a period of time, alternatively keep the project running manually. So, the interruption of system have small impact on water supply. In view of this, the specification does not have to make excessive requirements on the disaster recovery system to avoid the excessive cost of data zero-loss.

\section{Network and information security}

In recent years, the water conservancy industry has vigorously carried out the construction of information technology, all things have been or will be linked to the network. For water allocation project, the project covers a wide range and controls too many objects. The potential risk of information security is increasingly valued by engineers. ${ }^{[7]}$ In order to design a safe information system, the design requirements of network security system should be clarified in design specification. Therefore, it is suggest that the security system should include physical security, network security, system security and application security. Security system of large-scale project should be configured hardware firewall, anti-virus software, intrusion detection, network security auditing, vulnerability scanning etc., and encryption transmission measures should be adopted when the sensitive information is transferred. Medium-scale projects may implement the suggestions by reference.

\section{Geographic information system(GIS)}

GIS realized the combination of graphics and data. In information system of water allocation project, GIS is an interactive interface displaying project layout and presenting operation parameters. 
In the current design, there are 2D and 3D application of GIS. According to the survey, most of the operators have indicated that 2D GIS can sufficiently meet the needs of project monitoring. Although 3D GIS systems can demonstrate the operational characteristics of the project better in a threedimensional manner, if the real-time interaction is implemented, the hardware performance of the system is high demanding, inevitable to increase costs. So far, the attempting from 2D GIS to 3D GIS has not provided users with smoother application experience. Therefore, this paper suggests that 2D GIS should be recommended in design specifications.

\section{Building information model (BIM)}

BIM connects the data, process and resources of the whole life cycle of engineering. From engineering design, construction to operation and maintenance, it is based on the refined BIM model. By pushing from the national level, BIM has been widely used in architectural engineering. Therefore, this paper suggests that in the case of small investment impact, the application of BIM should be encouraged, but at the same time, it is clear that BIM cannot be simply used as a three-dimensional display means, which will lose the real meaning of BIM. At present, many companies have adopted the 3D design software (Revit, Bentley, CATIA, etc.), which is of great help for the later development of 3D application, for example, the integration of BIM and 3d GIS can manage the macro geographic information and the micro structure.

\section{Virtualization technology}

Virtualization has a history of decades, but it has become a hot technology today. It has many advantages such as integrating hardware resources, reducing the total cost of ownership and improving the system availability. At present, the water allocation project information system has just started trying application of virtualization technology. The virtualization technologies involves server virtualization, network virtualization, storage virtualization, desktop virtualization. The author believes that in the early stage of technology application, guidance can be made timely by design specification, so as to make the new technology play a more reasonable role and promote the development of water informatization.

This paper considers that the core functions of water allocation project information system are monitoring of hydraulic structure, controlling of electromechanical equipment, dispatching of water resources, which have more characteristics of industrial control network. According to the relevant requirements, there must be a physical isolation device between control network and management network, which is normalization in the design of large-scale water allocation project information system. Therefore, it is more reasonable that the control services related to monitoring and dispatching should be run on the physic system. For the services running on the management network, it is hard to directly stipulate whether virtualization technology should be applied. The usage of virtualization technology should be determined by technical and economical comparison.

\section{Conclusion}

Water allocation projects redistribute limited water resources to meet water demands in dry lands. Throughout the project dispatching and operating process, the operator can obtain an optimal dispatching solution under lots of optimization objects through the information system, and selectively apply it in combination with their own operational experience to ensure that the water resources are scientifically and reasonably allocated.

At present, the design criteria of water allocation project information system is not yet standardized. Different design companies or different designers have different opinions on several key aspects of system design. This not only brings inconvenience to projects' standardized operation and management in future, but also brings difficulties to the development of universal business application, and ultimately affects the development process of water informatization. Therefore, it is 
feasible that this paper considered to constrain and guide the design of the system by formulating a design specification of information system in order to achieve the design standardization. At the same time, this paper proposed some suggestions to how to compile a design specification of information systems, which can effectively regulate the design process of information systems and make information system play a better role in the process of water resources allocation.

\section{References}

Xuehong Wen, Discuss on Demand Design of Automatic Information System in Modern Water Conservancy Projects, Water Resources Informatization. No.4 (2014) 64-68.

Xiaobing Zhou, Lide Zhang, Guanglin Liu, Management Information System for Long Distance Water Diversion Project, China Water \& Power Press, Beijing, 2007.

SL 430-2008, Design guideline for water diversion project, China Water \& Power Press, 2008.

Chen Zhang, Study on the Security of Water Quality and Application for Long Distance Water Diversion Project, Tianjin University, 2008.

Liangfang, Haozhi Fan, Lin Zhao, Feasibility and Necessity Study of Optical Fiber Communication Technology in the Water Diversion Project in the Application, Transportation Science \& Technology. Jul. 2008, 115-117.

Shunxiang Zheng, The application of modern communication Technology in Water Conservancy, Shandong University, 2012.

Zhiyuan Ren, Safety Analysis and Protection of Industrial Network in Water Supply and Drainage Projects, China Water \& Wastewater. Vol.32 No.8 (2016) 119-121. 